\title{
Dados de tuberculose do Estado de São Paulo
}

\section{Data on tuberculosis in the state of São Paulo, Brazil}

São Paulo, 6 de novembro de 2007.

Prezados Editores,

Parabenizamos os editores desta conceituada revista por dedicarem este suplemento à tuberculose, doença que, como se sabe, tem relevância nacional e internacional como problema de saúde pública.

Sabendo que serão analisados e publicados nesta revista dados de tuberculose do Estado de São Paulo, cuja participação no total de casos do país atinge cerca de $20 \%$, cumpre esclarecer alguns pontos relevantes.

São Paulo começou a utilizar desde 1996 um sistema para computação dos dados de tuberculose construído em EPI-INFO, chamado EPI-TB.

Quando foi implantado o SINAN na vigilância epidemiológica em âmbito nacional, verificou-se que o mesmo não atendia a todas as necessidades deste Estado, uma vez que os indicadores já então utilizados para monitoramento da doença não eram contemplados no SINAN em sua totalidade. Dados sobre a descoberta de casos e resultados de teste de sensibilidade, por exemplo, não eram coletados pelo SINAN.

Acordou-se então com o Ministério da Saúde que a base de dados estadual seria convertida para o SINAN e enviada periodicamente para ser incorporada à base nacional.

Ocorre que essa operação apresentou problemas, pois seriam necessários procedimentos especiais em âmbito do DATASUS. Casos já excluídos na base estadual, por exemplo, permaneciam na base de dados nacional, gerando duplicações de registros. Outros problemas foram detectados, tais como disparidade de informações entre os dados de desfecho de tratamento no banco de dados estadual e federal.

No entanto, o Programa Nacional de Controle da Tuberculose, reconhecendo o esforço e a qualidade das informações de tuberculose de São Paulo, premiou o Estado por possuir informação sobre encerramento de mais de $90 \%$ dos casos do ano anterior.
A avaliação dos principais indicadores epidemiológicos e operacionais do Estado, referendada por epidemiologistas de renome, foi publicada no Boletim Epidemiológico Paulista (BEPA), e mostra que a tendência da endemia no Estado é de declínio. Por outro lado, as taxas de cura apresentaram tendência de aumento significativo no período de 1998 a 2004. Esta avaliação conclui que o desempenho do referido programa temsido satisfatório.

É claro que, com cerca de 17 mil casos novos e 3 mil retratamentos por ano, este Estado tem que lidar constantemente com a multiplicidade de registros, decorrente da mobilidade dos pacientes pelos mais de 600 municípios. Para minimizar este problema, desde 2004 conta com um novo sistema, o TBweb, no qual as notificações são feitas "on-line", via internet. Este novo sistema funcionou inicialmente em paralelo ao EPI-TB e, a partir de 2006, substituiu-o definitivamente. Com vantagens incontestáveis como a unicidade de registros de cada paciente e comunicados automáticos por ocasião de transferências e hospitalizações, o TBweb tem trabalhado com um banco único de dados, o que garante dados mais oportunos e comunicação entre os diversos níveis de vigilância.

Dos casos 15700 casos novos cujo início de tratamento ocorreu em 2006, somente 1412 (ou seja, 9\%) não tinham informação sobre desfecho até outubro de 2007. Em resumo, apesar das dificuldades de repasse dos dados para o nível federal, o sistema de informações nos parece adequado à realidade de São Paulo e tem melhorado ano a ano em relação à confiabilidade $\mathrm{e}$ oportunidade.

Mais uma vez, gostaríamos de ressaltar essa iniciativa da revista, colocando em pauta um assunto tão importante para a saúde de nossa população.

\section{Vera Maria Neder Galesi}

Coordenadora do Programa de Controle da Tuberculose do Estado de São Paulo 